the taking of antibiotics, albeit there is evidence in other papers that the tetracyclines, and chloramphenicol in particular, have demonstrable effects on mitochondria and molecular transcription. Another important paper is that by Choi et al. on congenital central nervous system malformations in Manitoba, which they find to be associated with low maternal calcium levels.

The book is completed by a useful list of participants and an inadequate index which is not a helpful guide to the contents.

Taken as a whole, this book is likely to be of value mainly to obstetricians, paediatricians and experimental pathologists interested in teratology for whom it provides a helpful set of references and a guide to work and workers in their field. Disappointingly it deals only superficially with the mode of action of teratogenic agents either from the point of view of pharmacology or embryology; and of course it is already partly out of date.

The price is on the steep side for what is essentially an ephemeral source of information, albeit it is well produced and surprisingly easy to read considering that many contributors are not using their own language. The publishers should change the "blurb" on the dust jacket which is almost totally misleading.

$$
\text { J. Davis }
$$

\section{Muscle Sense}

Mammalian Muscle Receptors and Their Central Actions. By Peter B. C. Matthews. Pp. $\mathrm{x}+630$. (Edward Arnold: London, 1972.) $£ 9$.

IT is a remarkable testimony to the complexity of the sensory receptors of muscle and to the difficulty of their experimental study that after some hundred years of research so much is known yet so much remains to be settled. The story of this research as told in Dr Peter Matthews's words forms an absorbing example of the way in which a biological science typically progresses. A most helpful feature of the book is that a historical path is marked through the maze of detail which would otherwise be so confusing. We see how a limited level of understanding was reached by micro-anatomical study, but that further advance had to await the new techniques of electrical recording in the 1930s. A period of rapid advance followed until by 1960 the understanding of muscle spindles had reached a stage consistent enough perhaps to satisfy the less enquiring mind and to justify calling it the "classical picture". In this, the spindle consisted of special muscle fibres bearing two types of sensory endings and a motor supply. Two new developments then took place to cause renewed interest, which is still maintained. The intrafusal muscle fibres were shown to be of two kinds and the motor innervation was found to have unexpected complexities.

The whole subject is dealt with in a most scholarly manner and with the critical insight which we would expect from Dr Matthews, who has contributed such a large part of our original knowledge of the muscle receptors in recent years. There is a temptation in any subject as complex as this for the individual research worker to embark on a solitary exploration of some aspect which, while interesting in itself, is not on the direct route to the most rewarding objectives. There are, for example, the very interesting questions of the biophysics of the origin of the receptor potential and the initiation of nerve impulses in the spindle. There are the questions of the exact distribution of motor fibres to intrafusal muscle fibres and the origins of velocity sensitivity. These problems continue to engage the attention of many workers and $\mathrm{Dr}$ Matthews does them justice in appropriate chapters, but he is not sidetracked by them. Instead the development of the material is followed logically to the final chapters concerned with the place occupied by the muscle receptors in voluntary muscle control. These contain an admirable and fairminded presentation of a difficult subject, although there may be some disappointment that control engineering principles are not better presented. It is true that oversimplification is difficult to avoid in applying such principles in this area, but without them the ideas of servo control and servo assistance are really beyond intuitive grasp. Much argument has centred on attempts to demonstrate that voluntary movements may be driven through the fusimotor route. The view, as originally stated and since repeatedly implied, was that it is only by driving by this route that the advantages of a servo control are made available. The control engineer would not take this view, because if the only function of the fusimotor drive were to provide a "bias" on the spindle output as an excitatory input to the motor neurones, this could just as well be sent direct to the motor neurones. Of course, muscle spindles tend to be silenced by muscle shortening so that $\alpha-\gamma$ linkage may be desirable to keep spindles active during shortening to maintain feedback control. But this is already achieved in amphibians without a special fusimotor system. The implication therefore is that the mammalian fusimotor system must have other significance. Dr Matthews does arrive at virtually this conclusion, but he might have done so more directly from control engineering principles. Nevertheless, the author has done great service, to those seeking to use control systems analysis methods, by his work on transfer function estimation by measuring the small amplitude vibration sensitivity of spindles. The sinusoidal testing method is described and the results which at first sight conflict with those of larger scale transient testing are explained, at least in part. Readers should be warned of a small error in the expression quoted for the response amplitude as a function of frequency.

This work is going to be of lasting value to research workers and students for many years. It expands and updates the author's widely quoted review of ten years ago and leads us to hope that perhaps ten years from now a further volume will appear with the answers to many of the problems which are formulated in such precise terms in this one.

A. TAYLOR

\section{Explanation in Science}

Causality and Scientific Explanation. By William A. Wallace. Volume 1. Medieval and Early Classical Science. Pp. $x i+288$. (The University of Michigan: Ann Arbor, November 1972.) $\$ 12$.

THIs is the first of a proposed twovolume work, the thrust of which is to demonstrate the continuing role which the notion of causality has played in discussions of scientific explanation from antiquity to the twentieth century. In developing his theme Professor Wallace attempts to combine the analytic approach of the philosopher of science with the factual one of the historian of science. His principal thesis is that causal explanations continued to have a more important function in science after the Middle Ages than is normally admitted. Before the second volume appears one cannot say how successful he is and, indeed, the burden of proof lies in showing that causal explanations continued to have importance in the development of postNewtonian science.

This volume does show quite convincingly that causal explanations retained an important position in seventeenth-century scientific thought, for example in Galileo, Harvey and Newton. Once one penetrates a bit beneath the surface of these writers a strong motivation to put forth causal explanations is found to persist in spite of various denials.

Leaving aside the central thesis, it can be read as a connected treatment of scientific methodology from Aristotle to Newton. As such it is most useful, especially since it is based on a wide reading of little known primary sources and some of the best recent secondary literature. Several particular aspects of Wallace's work are noteworthy. First, it stresses in convincing fashion a continuity between mediaeval and 